\title{
A conceptual framework on health professionals' engagement towards pharmacovigilance: a qualitative exploration
}

\author{
Swagatika Priyadarsini Swain, Kripalini Patel, Subrata Kumar Palo, \\ Bijaya Mishra, Sanghamitra Pati*
}

ICMR-RMRC, Bhubaneswar, Odisha, India

Received: 28 July 2021

Revised: 07 August 2021

Accepted: 13 August 2021

*Correspondence:

Dr. Sanghamitra Pati,

Email: drsanghamitra12@gmail.com

Copyright: (C) the author(s), publisher and licensee Medip Academy. This is an open-access article distributed under the terms of the Creative Commons Attribution Non-Commercial License, which permits unrestricted non-commercial use, distribution, and reproduction in any medium, provided the original work is properly cited.

\section{ABSTRACT}

Background: With the growing reliance on drug therapy in the recent era, the safety of medications is one of the vital parameters for the success of any medicine. Considering this, pharmacovigilance (PV) was developed to provide adequate identification, reporting, evaluation, and understanding of adverse drug reactions (ADR). The objective of this study was to understand the opinion of health care providers on PV, the current reporting mechanisms, identifying the causes for underreporting, and the existing process in clinical practice.

Methods: A qualitative study using pretested interview guide was conducted among 20 different cadres of healthcare personnel (doctors, pharmacists, and staff nurses) from various hospitals such as government, private, corporate, and medical college of Odisha state. The data were analysed using a thematic analysis. The meaning units have been identified from the transcript and coded with MAXQDA software (MAXQDA Analytics Pro 2020, VERBI GmbH Berlin).

Results: Participants showed a lack of awareness regarding the concept of PV. A cluster of challenges such as lack of ADR monitoring, non-conducive work atmosphere and lack of cooperation between staff, lack of knowledge among the health professionals, and fear of legal liability as major pitfalls causing poor ADR reporting. To enhance the pharmacovigilance practice, participants suggested context-specific strategies such as IEC activities, innovative ideas to improve ADR monitoring, regular monitoring.

Conclusions: Capacity building through training, regular monitoring and supervision to strengthen the pharmacovigilance practices is the current need in India.

Keywords: Pharmacovigilance, Adverse drug reaction, Drug safety, Pharmacovigilance programme of India

\section{INTRODUCTION}

Adverse drug reactions (ADRs) have recently gained attention due to potentially fatal complications resulting from drug therapy). Globally, ADR is recorded among $1.7 \%-32.7 \%$ of hospitalized cases, and among all ADR cases, $2.5 \%-21.4 \%$ require hospitalization. ${ }^{1}$ The changing regulatory landscape has led to advanced, vigilant, effective, and more relevant options. They not only align with risk assessment of the drugs through better monitoring and assessing the pattern of drug utilization but also satisfy vital regulatory requirements for marketing and execution needs for patient safety. ${ }^{2}$

Even though a drug passes through a strict regulatory procedure of clinical trial and provides evidence of efficacy and safety of the drug for its approval, it does not 100 per cent guarantee its security. Therefore, pharmacovigilance has an essential role in ensuring a drug's safety by closely monitoring for any untoward 
reaction due to the medication. ${ }^{3}$ The Central Drugs Quality Control Organization (CDSCO), New Delhi, under the Ministry of Health and Family Welfare, Government of India, unveiled a national pharmacovigilance program in July $2010{ }^{4}$

The program aims to detect, anticipate, explain, and prevent any adverse drug event (ADE) at the earliest by implementing and ensuring ADR reporting before harming many. Despite the pharmacovigilance programme, the under-reporting of ADR has been a significant issue in India. In India, the reporting of ADR ranges from 3.7\%$32.7 \%$ only. ${ }^{5,6}$ Various factors play a crucial role in reducing low ADR reporting substantially on pharmacovigilance utilization. As a result, it poses difficulty in estimating the incident rate, understanding the population exposed to the drug and type of adverse reactions in detail. ${ }^{7}$

With this backdrop, our qualitative study aimed to understand the opinion of health care providers (doctors, pharmacists, and staff nurses) on pharmacovigilance, the role of key stakeholders, the current reporting mechanisms, and the causes for underreporting and the existing process in clinical practice.

\section{METHODS}

\section{Study design, settings, and participants}

A qualitative study using a pre-designed and pretested interview guide was conducted among different cadres of healthcare personnel from May 2020 to December 2020. Health care personnel aged $>18$ years and who gave their consent were included in the study.

The participants were selected by purposeful sampling from various hospitals such as government, private, corporate, and medical college hospitals in Odisha, India, to comprehensively understand the diversity of practices across different health facilities in the state. The study participants were the doctors, pharmacists and nursing staff from various departments such as medicine, surgery, obstetrics and gynaecology. Considering the COVID-19 related restrictions, under the study, an in-depth telephonic interview was done among a total of 20 participants till there was data saturation. All participants were informed about the purpose of our research, and their verbal consent was recorded prior to their voluntary participation.

\section{Data collection procedure}

An open-ended interview guide was developed through a consultative and interactive process. A total of 20 in-depth telephone interviews (IDIs) were performed. Interviews were conducted by the first two authors, who were native to the study settings, having command of the local language and specialized degree in clinical and public health nursing.

\section{Data management and analysis}

All interviews were audio-recorded, transcribed, and translated into English. The data were analyzed using thematic analysis. The meaning units have been identified from the transcript and coded with MAXQDA software (MAXQDA Analytics Pro 2020, VERBI GmbH Berlin). The findings were reviewed and discussed among all the researchers, and the themes and categories were finalized. The transcripts were read several times to understand the exact meaning and recognize the related phrases in general terms. Integrity was acquired through peer debriefing to improve trustworthiness.

\section{Ethical consideration}

Ethical approval for this study was obtained from the Institutional Review Board of ICMR-Regional Medical Research Centre. The study objective was explained to the participants, and their verbal consent was obtained prior to the interview. All participants participated voluntarily in the study without any incentive.

\section{RESULTS}

Three main themes were derived: (1) importance of ADR reporting; (2) barriers to ADR reporting; and (3) strategies to improve ADR reporting.

\section{Table 1: Themes.}

\begin{tabular}{|c|c|c|c|}
\hline Themes & Importance of ADR reporting & Barriers to ADR reporting & Strategies to improve ADR reporting \\
\hline $\begin{array}{l}\text { Sub- } \\
\text { themes }\end{array}$ & $\begin{array}{l}\text { - Familiarity with medication } \\
\text { safety and ADR concept } \\
\text { - Perception about ADR } \\
\text { reporting } \\
\text { - Practice on ADR reporting }\end{array}$ & $\begin{array}{l}\text { - High case load } \\
\text { - Lack of reporting } \\
\text { system/poor governance } \\
\text { - Lack of education and } \\
\text { training } \\
\text { - Legal liability and lack of } \\
\text { accountability }\end{array}$ & $\begin{array}{l}\text { - IEC activities } \\
\text { - Innovative ideas to improve ADR } \\
\text { monitoring } \\
\text { - Regular monitoring and review }\end{array}$ \\
\hline Codes & $\begin{array}{l}\text { Knowledge, perception of } \\
\text { awareness, interest to carried out } \\
\text { the activity }\end{array}$ & $\begin{array}{l}\text { reporting system, need for } \\
\text { practice, } \\
\text { environment, no idea, weak PV } \\
\text { policy, dilemma of disclosure. }\end{array}$ & $\begin{array}{l}\text { Training, course curriculum, regular } \\
\text { vigilance, system change is needed. }\end{array}$ \\
\hline
\end{tabular}




\section{Theme 1: Importance of $A D R$ reporting}

\section{Subtheme 1: Familiarity with the ADR concept}

All the health care providers especially those treating the patients should know and practice Pharmacovigilance (PV) related activities to ensure patient safety. ${ }^{8}$ Unfortunately, similar level of awareness was not found among majority of the study participants. Though some doctors knew about ADR and PV, most participants did not even know about the term PV and ADR. "I don't know about the reporting system, only adverse drug reaction I know" (Pharmacist). Somewhere the participants also explained the organizational accountability to conduct training and workshops related to the ADR reporting system, which could improve their orientation on the topic. In this regard, participants blamed their institution/health facilities for having improper regulatory mechanism. When the participants were asked about what they understand by adverse drug reaction, they stated, "One training program was conducted related to this but I did not attend that, and I vaguely remember about that. I can't tell in detail. However, in my clinical practices, I have never seen anyone who is practicing the ADR reporting" (Staff Nurse working in govt.)

Most of the physicians had clear understanding about adverse drug reactions because of their clinical knowledge and practice, however, their practice on reporting ADR case was not evident. In this regard, a physician stated, "I haven't seen anyone died because of ADR. Also, if you ask me about the reporting system, no such system has been developed till now according to me" (Medicine specialist working in Govt hospital). The importance of reporting the ADR cases had not been understood by most of the respondents. They believed that all the drug related adverse reactions were included in the drug pamphlet hence it was irrelevant to mention it again in the patient case sheet. "Once I met with an accident and while taking medicines, I suffered from skin allergies. For that, I was administered with steroids. But during that time nobody was reporting it. I had only discussed with the doctor"(Pharmacist working in govt.).

\section{Subtheme 2: Perception about ADR reporting}

The perception towards reporting the ADR cases was varied among the participants. According to some, only the life-threatening reactions should be reported in detail. In contrast, others told that every single case of adverse reaction should be reported even if it is not life threatening.

\section{Importance in clinical practice}

The lack of accountability for reporting the adverse drug reaction was a major issue for its no practice. Also, the hierarchical structure in an organization defines the workload of the health care provider. So, reporting ADR should be the mutual responsibility of all medical professionals and all the health care professionals keeping the safety of patients on priority. "At first, a staff nurse manages the cases, provide medications and injections. If some adverse reaction happens, then they should know how to manage it properly" (Physician working in pvt. facility).

The biggest deterrent to ADR reporting was establishing the association that the ADR is due to the particular drug. "When we record all the adverse reactions and medications, at least we could know for which group of medicine or which particular person is showing the adverse drug reaction" (Gynaecological specialist working in private hospital). Some participants acknowledged that the patients' history about drug allergies/reactions is not obtained in many instances. This might further worsen the patient's health condition. " $A$ patient should not suffer with severe adverse reaction of a medication which could lead to further anaphylactic shock. These things we could prevent. So definitely this ADR reporting should be practiced in clinical setting" (Staff nurse working in private hospital). Some participants rationalized the reason for poor ADR reporting to lack of sufficient forms provided by the department. "Occasionally from the pharmacology department forms are provided. But we are not fully aware of it. Recently I came to know about the form from my pharmacist friend" (Paediatric specialist working in govt. hospital).

Almost all the physicians had a positive attitude towards ADR reporting. However, surprisingly some physicians had never seen the ADR form for reporting. This reflects the system side flaws in engaging the health care professionals under the pharmacovigilance programme. "No. no such form I have ever seen in my entire 30 years of careers" (Pulmonary medicine specialist working in govt. hospital)

\section{Subtheme 3: Practice on ADR reporting}

\section{Individual basis}

When it comes to ensuring professional responsibility for ADR reporting, most government hospital doctors opine that this responsibility is beyond the boundaries of their job obligations. In contrast, the private health care personnel had a much greater conviction that ADR monitoring is an ethical duty. "once we purchase medicine and, in that batch, all the medicines where showing adverse drug reaction. So, we informed it to the pharma company. Then they changed it and supplied a new batch medicine" (Medicine specialist of private hospital). Some participants ignored the importance of documenting ADRs because they do not have the expertise to determine. They did not know which ADRs has to be reported and what to not report. Doctors undermined the importance of other health professionals in ADR reporting in most of the circumstances. "I have theoretical knowledge but in my clinical practice I have never practiced it" (Surgery 
specialist working in govt. Hospital). "In my hospital, no such thing is going on. We do not report these things. What medicines are to be provided for case management, they are noted down on patient case sheet. If we could manage then that's good else, we refer the patient" (Staff nurse working in govt. hospital). A few participants highlighted a continuous program for pharmacovigilance training and supervisory activities in some formal private facilities. They also believed that there should be a supervisory team to follow up the reporting activities regularly. "I am the nursing Superintendent. I am looking for more awareness among the nurses, because there is very big team of nursing here. They need to know the channel and system for reporting so that we could take immediate action and save the patient" (Staff nurse working in private hospital).

\section{Private verses government}

The private physicians were found to better understand the concepts of ADR and better intent for engaging in PV practices compared to their government counterparts. "No one is practicing this. But if it is important then I need to discuss it with the pharmacology department of my hospital, but I have never seen anyone who is practicing this" (government physician). We noticed that most of the staff nurse participants from private hospital take immediate action whenever there is any adverse reaction. They fill in the ADR form provided by their department and inform to their superior authority. In the patient case sheet, they mention about the ADR and restrict the use of the suspected drug for the patient. "If there is any ADR, it is immediately attended by the treating and the details are filled in. Immediately the drug is stopped for further use (Nurse working in private hospital).

\section{Theme 2: Barriers to ADR reporting}

We noticed a cluster of challenges such as lack of ADR monitoring; non-conducive work atmosphere and lack of cooperation between staff, poor communication among staff, lack of knowledge among the health professionals, and fear of legal liability as major pitfalls causing poor ADR reporting.

Subtheme 1: High case load

Most of the physicians recognized that, increased workload as a major barrier for reporting adverse drug reaction cases. Some participants argued that they knew the importance of reporting, but they were not committed to ADR reporting because of their busy working schedule. "I think professionals do not like to do paperwork during the busy schedule, but yes even if not all the adverse reaction cases are documented, few cases should be documented (Physician working in govt. hospital).

\section{Subtheme 2: Lack of a reporting system}

Participants highlighted that lack of clear guidelines and poor governance system as a major barrier for smooth reporting of $\mathrm{ADR}$. In this regard, some participants suggested creating a special committee responsible for investigating and monitoring the ADRs at facility level. Their views were like: "The only issue I faced was, the form was not available in appropriate time. And second point is, once we fill in the form, who will also carry it to the pharmacology department? A clear protocol is not available. So, for these things many of the professionals don't have the interest to practice the ADR reporting" (Physician working in govt. facility).

\section{Subtheme 3: Lack of education and training}

Many participants agreed that the cause of no ADR reporting could be due to the lack of education and training on the topic. Participants from the academic sectors recommended for an intensive program on pharmacovigilance among all health care professionals. "A onetime training or such small discussion on this topic will not help much. My seniors just informed me verbally that if any reaction happens, we need to fill in the form and send it to the pharmacology department. That's it" (Staff nurse working in govt. hospital).

\section{Subtheme 4: Legal liability and lack of accountability}

According to many physicians, a fear of legal liability contributes to less or no reporting on ADR cases. Participants suggested for a facility level special investigating team would assess this issue. "When someone asks and enquires on this reporting, then the forms get filled-in, but not in other times. Moreover, I think for this no one has been held accountable" (General physician working in Govt. hospital). Participants were asked about the lead role for medication safety; many physicians opined that pharmacists should be accountable for medicine safety in a hospital ward. They were trained professionally on this particular subject. But when the same question was asked to the pharmacist working in a private hospital, he narrated, "We do not do this $A D R$ reporting because we don't even know that such reporting system is present, and we are supposed to practice it. Moreover, we were never given importance. So, we should not take any risk. So, this is the main challenge" (Pharmacist working in private hospital).

\section{Theme 3: Strategies to improve ADR reporting}

To enhance the pharmacovigilance practice, various context specific strategies need to develop and strictly adhered. The participants of our study suggested for different strategies to improve the pharmacovigilance activities in clinical settings.

\section{Subtheme 1: IEC activities}

Lack of understanding of the importance and knowledge of pharmacovigilance became an important barrier for ADR reporting. To address this, most of the study participants suggested adequate and proper training to the 
health professionals by the experts. One physician suggested- "Definitely government should take a decision on that. There should be repeated training or workshops for all responsible professionals" (Paediatric specialist working in govt.).

\section{Subtheme 2: Innovative ideas to improve ADR monitoring}

Participants suggested some innovative changes in the ADR reporting system, such as establishing an online ADR reporting system that will address availability. A participant suggested- "If the ADR form could be attached to the patient case sheet along with a list of important drugs, it would be easier for reporting. Also, that would be helpful while treating the patient (Gynaecology specialist working at private hospital).

\section{Subtheme 3: Regular monitoring and review}

According to some participants, regular monitoring of the pharmacovigilance activities and monthly review will give promising improvement in adherence and practice of ADR reporting. Also they emphasized for having a dedicated staff for this who could also be accountable for the reporting. A critical care specialist suggested- "I think a dedicated unit should be developed for this, in every department, an accountable person should be provided by the hospital who could look after the ADR reporting", (Critical care specialist working in private hospital). Some of the participants also opined for a change in the flow of reporting. For instance, nursing officer has to inform the shift in charge, then the shift in charge will inform the senior nursing officer. Also, a quality team needs to be created including a Nursing Officer, Senior Nursing Officer, and a physician. All cases of ADR will be finally reported to the quality assessment team for taking action. One staff nurse suggested- "Streamlining the reporting system should be done first. After that only this could be implemented properly by the staff in the hospital." (Staff nurse working in government facility).

Table 2: Demographic details of participants.

\begin{tabular}{|lll|}
\hline Variables & N $($ Total $=20)$ & Percentage $(\%)$ \\
\hline Gender & & \\
\hline Male & 13 & 65 \\
\hline Female & 7 & 35 \\
\hline Age (years) & & \\
\hline Mean \pm SD & $36 \pm 1.22$ & \\
\hline
\end{tabular}

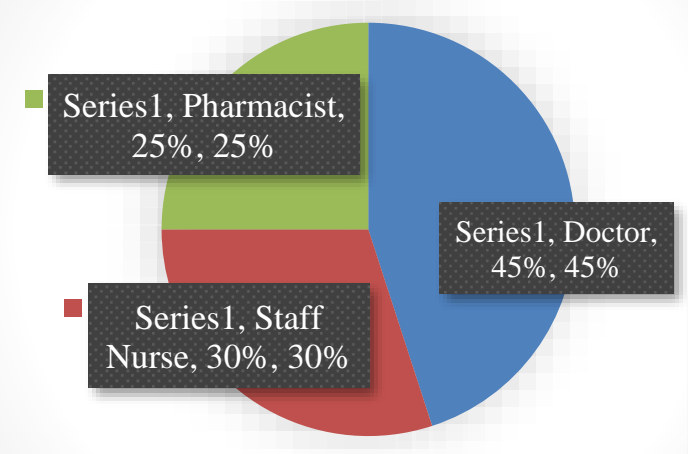

Doctor $\square$ Staff Nurse $\square$ Pharmacist

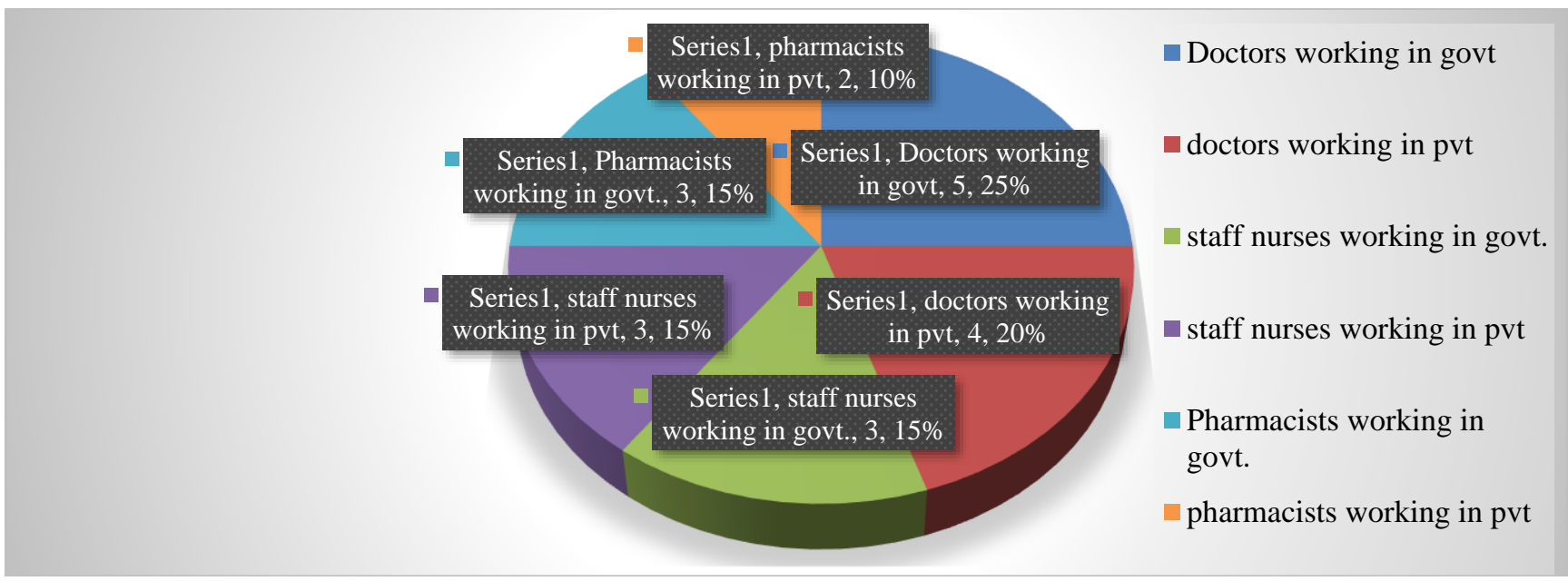

Figure 2: Facility wise distribution of participants. 


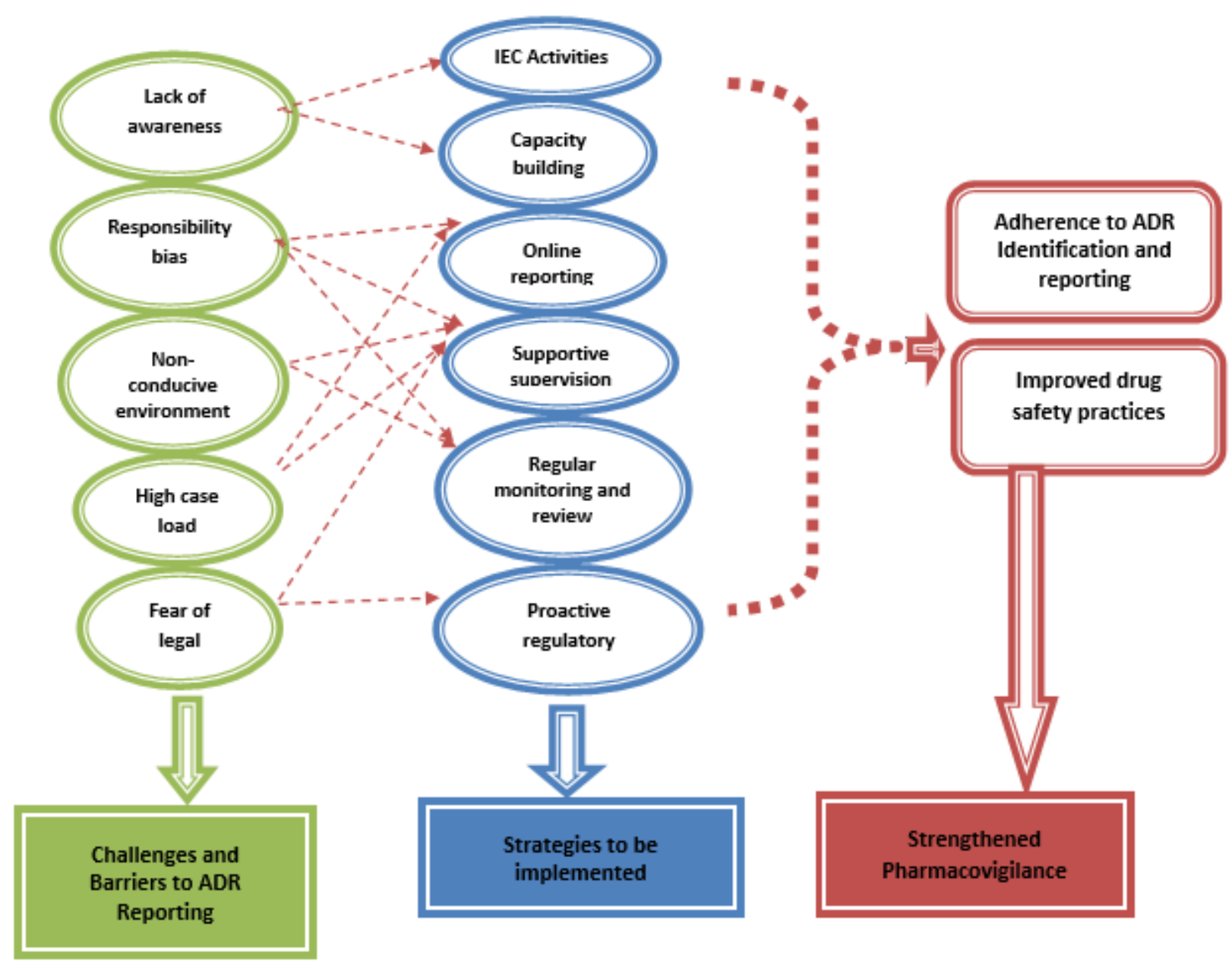

Figure 3: A conceptual framework to strengthen pharmacovigilance activities among the healthcare providers.

\section{DISCUSSION}

Pharmacovigilance is the science and activities relating to detecting, assessing, understanding, and preventing adverse effects or any other medicine/vaccine related problem. ${ }^{9,10}$ With so many types of drug molecules and drug brands including generic drugs used in clinical practice, it is utmost important to have a robust system for recording and reporting any ADR suspected due to use of a drug. ${ }^{11}$ To address this in India, pharmacovigilance program has been implemented since 2010. In spite of the fact that more than a decade has passed, no remarkable change on this aspect is observed in clinical practice. To the best of our knowledge, this study is the first ever effort in Eastern India to explore the perception and practice of pharmacovigilance among healthcare professionals working in different health facilities.

Though most of our participants had a positive attitude for practicing ADR reporting due to their understanding of its importance, there were few aware of its processes and procedures. This prevented them from ADR reporting. Participants also highlighted other factors such as absence of such practice in their working environment; lack of availability of reporting forms; no knowledge on what, how and whom to report; lack of time for such reporting due to workload; and fear of legal implications hindrances for ADR reporting. Such poor reporting practice was more evident in government health facilities compared to private hospitals. The professionals of private set up are regularly trained on pharmacovigilance, ADR reporting through trainings and workshops.

The ADR case recording, and reporting are regularly monitored and supervised in private hospitals. These are observed as the major reasons for such difference in practice between government and private health facilities. Moreover, we could also notice that factors like minimum concern about personal security among the private professionals and low level of accountability among the professionals of government facility compared to their counterparts as other important reasons for such difference. Regular monitoring and handholding support, ensuring availability of the ADR reporting forms, and ensuring security of the professionals, especially those in government facilities, would encourage them to record and report the ADR cases. The issue of fear towards legal implications on recording and reporting could be overcome if the system will have a supportive atmosphere towards ADR reporting under patient safety promotion. 
According to a research study, ADR-related misconceptions and inaccurate reporting result from lack of important information about its etiologies, medical history, and drugs..$^{9,12-14}$ However, we found that the physicians have adequate knowledge to detect and manage the ADR. This shows that it is not only the knowledge about detecting and managing ADR cases ensures practice of ADR recording and reporting but also having an indepth understanding on the topic is equally important. According to a study from India, the monthly rate of ADR reporting improved after the information related to ADR was published in the Pharmacovigilance Programme of India (PvPI) Newsletter, leading to more awareness campaigns circulars to the ADR monitoring center. ${ }^{15}$ Other than the doctors, pharmacists and nurses also greatly assess for any adverse reaction and reporting. However, we observed a clear dearth of awareness on the said topic among the pharmacists and nursing staff, on contrary to our finding, a research study done in United States (USA) indicated that the pharmacists to have the highest ADR reporting experience than the hospital doctors. ${ }^{16,17}$ So in India also their role with regard to ADR needs to be prioritized. In order to involve them actively, they need to be provided with proper training and handholding support through monitoring and supervision. In health facilities, the nursing staff are responsible for providing drugs to the patients and keeping their record. They also interact with the patients the most among health professionals. ${ }^{18}$

Considering the vital role that nursing staffs play in patient safety management, there is an urgent need to develop strategy for prioritizing their responsibilities towards ADR recording, reporting and managing, accordingly they need to be trained and supported. According to our study, one of the major impediments to the smooth reporting of ADRs is that the reporting department is open only from 9 A.M to 5 P.M and there is no clear instruction about what to do if any ADR happens during the other time. To address this, some physicians suggested for a centralized system for collecting data on ADR. Similarly, the nursing staff opined for transferring the ADR information to their reliever. In another study about the ADR reporting in Riyadh, Saudi Arabia, the staff nurses proposed keeping a special registry on ADR at all nursing stations. ${ }^{19,20}$ More than half of the participants were concerned about the big ADR forms required to fill in and the time required for doing it. This was also a key deterrent to reporting. As per Singh et al, they proposed including 58 items as "Generic ADR form" for universal reporting any/all ADR connected with marketed medications globally. ${ }^{4} \mathrm{We}$ also suggest revising the existing ADR form and making it standardized and simplified form better adherence and uniformity in reporting. This will also help in better monitoring and reporting of the ADR.

For better compliance to reporting, it is important to have a regular feedback and inputs from the regulatory bodies to the concern departments on the reported ADR. However, it was evident from our study that such flow of input is missing from the regulatory bodies. Similar issue has also been identified by a recent study about the lack of input from regulatory bodies on reported ADRs. ${ }^{21}$ Some physician participants of our study mentioned that they did not respond to their past reports, which discouraged them from future reporting. Considering the importance of ADR documentation and reporting and the existing workload among the health professional, some form of incentive to the reporting personnel would motivate them for improve this crucial yet neglected issue.

\section{Limitations}

The study made a unique qualitative contribution to the evidence-related to the current practices on pharmacovigilance among healthcare personnel in India. However, this study had some limitations. First, a small number of participants was interviewed which does not represent the population of the country. Second, all the interviews were conducted telephonically and in local language. Hence, some feeling and meaning might have been missed during the process of transcription.

\section{CONCLUSION}

With the increased medication practice and availability of several brands for a drug, it is critical to have pharmacovigilance practice in place at all the clinical settings. To achieve the same regular capacity building of physicians, staff nurses and pharmacists and regular monitoring and supervision is of paramount importance. A simplified and standardized ADR format will help improve adherence and uniformity in its reporting across all the health facilities. This will not only help in managing ADR cases but will also help in better monitoring and taking appropriate action to save others. To improve the prospective of healthcare professional from their early career, pharmacovigilance should be a part of the curriculum and prioritized subject for concern students.

Funding: No funding sources

Conflict of interest: None declared

Ethical approval: The study was approved by the Institutional Ethics Committee

\section{REFERENCES}

1. Giardina C, Cutroneo PM, Mocciaro E, Russo GT, Mandraffino G, Basile G, et al. Adverse Drug Reactions in Hospitalized Patients: Results of the FORWARD (Facilitation of Reporting in Hospital Ward) Study. Front Pharmacol. 2018;9:350.

2. Aljadhey H, Mahmoud MA, Alshammari TM, Dhaeefi M, Louet H, Gutthann S, et al. A qualitative exploration of the major challenges facing pharmacovigilance in Saudi Arabia. Saudi Med J. 2015;36(9):1097-102.

3. Opadeyi AO, Reglat A, Isah AO. Assessment of the state of pharmacovigilance in the South-South zone of Nigeria using WHO pharmacovigilance indicators. BMC Pharmacol Toxicol. 2018;19(1):27. 
4. Singh A, Bhatt P. Comparative evaluation of adverse drug reaction reporting forms for introduction of a spontaneous generic ADR form. J Pharmacol Pharmacother. 2012;3(3):228-32.

5. Singh J, Singh H, Rohilla R, Kumar R, Gautam CS. Lack of Awareness of Pharmacovigilance among Young Health-care Professionals in India: An Issue Requiring Urgent Intervention. Int J Appl Basic Med Res. 2018;8(3):158-63.

6. Abubakar AR, Simbak NB, Haque M. A systematic review of knowledge, attitude and practice on adverse drug reactions and pharmacovigilance among doctors. J Appl Pharm Sci. 2014;4(11):117-27.

7. Ganesan S, Sandhiya S, Subrahmanyam D. Frequency of ADRs and their Economic Impact in a Tertiary Care Public Sector Hospital in South India. SBV J Basic Clin Appl Health Sci. 2020;3(1):23-31.

8. Alshammari TM, Devadasu VR, Rathnam RP. Comparison of the safety information on drug labels in three developed countries: The USA, UK and Canada. Saudi Pharm J. 2017;25(8):1103-7.

9. Inacio P, Cavaco A, Airaksinen M. Current trends in pharmacovigilance: value and gaps of patient reporting. Int J Clin Pharm. 2018;40(4):754-7.

10. Davazdahemami B, Delen D. A chronological pharmacovigilance network analytics approach for predicting adverse drug events. J Am Med Inform Assoc. 2018;25(10):1311-21

11. Hartmann K, Pagliusi S, Precioso A. Landscape analysis of pharmacovigilance and related practices among 34 vaccine manufacturers' from emerging countries. Vaccine. 2020;38(34):5490-7.

12. Farha R, Abu HK, Rizik M, Aljanabi R, Alsakran L. Effect of educational intervention on healthcare providers knowledge and perception towards pharmacovigilance: A tertiary teaching hospital experience. Saudi Pharm J. 2018;26(5):611-6.

13. Nasir M, Zahan T, Farha N, Chowdhury AS. Acquaintance, approach and application of pharmacovigilance: questionnaire-based study at a tertiary care teaching hospital in Dhaka. Int $\mathrm{J}$ Basic Clinic Pharmacol. 2020;9(10):1497.
14. Adenuga BA, Kibuule D, Bamitale KDS, Rennie TW. Effective integration of pharmacovigilance systems at public health facilities in resource-limited settings: A qualitative study. Res Social Adm Pharm. 2020;16(8):1111-6.

15. Kalaiselvan V, Prasad T, Bisht A, Singh S, Singh GN. Adverse drug reactions reporting culture in Pharmacovigilance Programme of India. Indian J Med Res. 2014;140(4):563-4.

16. Callaghan J, Griffin BT, Morris JM, Bermingham M. Knowledge of Adverse Drug Reaction Reporting and the Pharmacovigilance of Biological Medicines: A Survey of Healthcare Professionals in Ireland. Bio Drugs. 2018;32(3):267-80.

17. Mota DM, Vigo Á, Kuchenbecker RS. Evolution and key elements of the Brazilian pharmacovigilance system: a scoping review beginning with the creation of the Brazilian Health Regulatory Agency. Cad Saude Publica. 2018;34(10):18.

18. Hadi MA, Neoh CF, Zin RM, Elrggal ME, Cheema E. Pharmacovigilance: pharmacists' perspective on spontaneous adverse drug reaction reporting. Integr Pharm Res Pract. 2017;6:91-98.

19. Sales I, Aljadhey H, Albogami Y, Mahmoud MA. Public awareness and perception toward Adverse Drug Reactions reporting in Riyadh, Saudi Arabia. Saudi Pharm J. 2017;25(6):868-72.

20. Khan LM, Harthi SE, Saadah OI. Adverse drug reactions in hospitalized pediatric patients of Saudi Arabian University Hospital and impact of pharmacovigilance in reporting ADR. Saudi Pharm J. 2013;21(3):261-6.

21. Belton KJ. Attitude survey of adverse drug-reaction reporting by health care professionals across the European Union. European J Clin Pharmacol. 1997;52(6):423-7.

Cite this article as: Swain SP, Patel K, Palo SK, Mishra B, Pati S. A conceptual framework on health professionals' engagement towards pharmacovigilance: a qualitative exploration. Int $\mathbf{J}$ Basic Clin Pharmacol 2021;10:1087-94. 